\title{
A method to study the possible effect of land elevation on cancer death rates in the U.S.
}

\author{
John F. Hart \\ Correspondence: jhartdc@yahoo.com

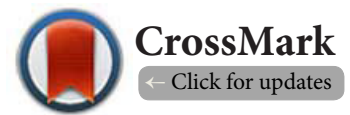

Hart Chiropractic Office Greenville, South Carolina 29615, USA.

\begin{abstract}
Background: Previous research revealed that cancer death rates tend to be lower in higher land elevation areas compared to lower land elevation areas. To further investigate this relationship, a novel method is used in the present study to identify low versus high elevation areas, with an accounting of air temperatures and smoking rates as other possible determinants of cancer.

Methods: Counties in the United States that did not have overlapping land elevations (in feet above sea level, determined at the state level) were identified and categorized as having either a "low" or "high" elevation. States that were outliers for temperature and smoking rates were omitted. Using an ecological design, county cancer age-adjusted death rates (per 100,000 persons) for white persons during 2006-2010 were compared in low versus high land elevation counties in states having similar smoking rates and air temperature.

$\underline{\text { Results: }}$ Cancer death rate for low land elevation counties ( $\mathrm{n}=584$ counties) was 189.6 (standard deviation [SD] 23.9) compared to the cancer death rate of 161.4 (SD 28.9) in high land elevation counties ( $\mathrm{n}=162$ counties), a difference that was statistically significant $(\mathrm{p}<0.0001)$ with a large effect size (of 1.12).

Discussion: Limitations to the study include: a) its (ecological) design, where populations, rather than known individuals are studied; b) the assumption that land elevations remain essentially unchanged over time; c) the assumption that the selected states had sufficiently similar temperatures and smoking rates; d) only one race (whites) was studied for the cancer death rates; and e) only one outcome (cancer death rates) was studied.

Conclusions: This study found lower cancer death rates in higher land elevation counties compared to lower land elevation counties, thus adding to the body of evidence on this topic. Ongoing research is indicated on the topic of land elevation-related health effects.
\end{abstract}

Keywords: Altitude, environmental factors, cancer epidemiology, physiological adaptation, methodological study

\section{Introduction}

Previous research has shown that cancer death rates tend to be lower in the U.S. for people living in higher land elevations [1]. This may be due to successful adaptation to stressors that accompany higher altitudes. These stressors include: a) low level (natural background) radiation, and b) decreased oxygen concentration.

Natural background radiation (NBR) consists of terrestrial and cosmic sources. The variable of altitude pertains to the cosmic source of NBR. At higher altitudes (higher land elevations), there is less atmospheric filter, thus increasing the amount of the cosmic source of NBR. The successful adaptation to low level radiation has been termed radiation hormesis [2]. Another theory is that decreased oxygen pressure acts as a trigger for the successful adaptation [3].

Other research has revealed a different clinical picture, where higher land elevation may be a risk factor for conditions such as COPD [4] and suicide [5]. Hence, the apparent mixture of potential risks and benefits of high altitude living warrants further research.
The present study uses the author's novel method of identifying: a) low versus high land elevation areas, b) states that have similar air temperatures and c) states that have similar smoking rates. In this way, an effect of land elevation (LE) can be better isolated, realizing of course that there are other potential determinants of cancer beyond air temperature and smoking. A similar method was used in a study on earlier death rate years (2002-2006) [6]. The present study differs from this previous study in that the present study: a) uses a more detailed numeric method for identifying low versus high LE counties, b) takes into account the two aforementioned other potential determinants, and c) uses more recent years for the cancer death rates (2006-2010).

\section{Methods \\ Cancer variable}

Average age-adjusted cancer death rates per 100,000 persons for 2006-2010 (the only years available in the database used) were obtained for U.S. counties for all ages, all cancer sites, white non-Hispanic persons, and both genders [7]. The limitation to a single race was done because: a) death rates tend to differ by 
race, and b) different races tend to live at different altitudes. For example, a higher concentration of black persons lives in the south, where LE is lower than Rocky Mountain states (Figure 1), whereas Rocky Mountain states have a higher concentration of white persons (compared to the southern states). The white race was selected because it provided the greatest number of counties reporting data. For the black race, only five counties met inclusion criteria (outlined below) in the high LE category compared to 147 counties in the low LE category.

\section{Land elevation variable}

States that did not overlap in their land elevations were selected so that clear differences could be established between LE areas for comparing their corresponding cancer death rates. Differentiation between low versus high LE states was performed by sorting their highest LE points in ascending order for the 50 states and District of Columbia ("states") [8] while also noting their corresponding lowest LE points. Sixteen states were found to not overlap in their land elevations, 11 of which were categorized as "low" LE states, while the remaining five were categorized as "high" LE states (Table 1).

As a further explanation of how states were included or excluded in this study, the next state highest point after Missouri's highest point of 1772 feet (Table 1), would be New Jersey's highest point of 1803 feet (New Jersey's lowest point=0 feet). New Jersey would overlap slightly with Montana's lowest point of 1800 feet (Montana is in the high LE category). All other states (that also would be sorted for their highest points in ascending order in Table 1) would likewise overlap with at least Montana in the high LE category. Montana could have been included in the low LE category but that would have increased the lob-sided counts between low versus high LE categories (county counts provided in Results). Missouri, with the highest high elevation point in the low LE category, could have been included in the high LE category, but its lower elevation points would have overlapped with the lower elevation points in many of the other low LE states (Table 1). Thus, the "cut-points" were 1772 feet (Missouri) for low LE states and 1800 feet (Montana) for high LE states (Table 1). As previously noted, all other states were excluded from the study because they would overlap with the high LE states.

\section{Temperature variable}

A map for cancer death rates (Figure 2) from which the data in this study were used, revealed a tendency for higher death rates in the southeast U.S. compared to Rocky Mountain states. This latter group (Rocky Mountain states) comprised all high

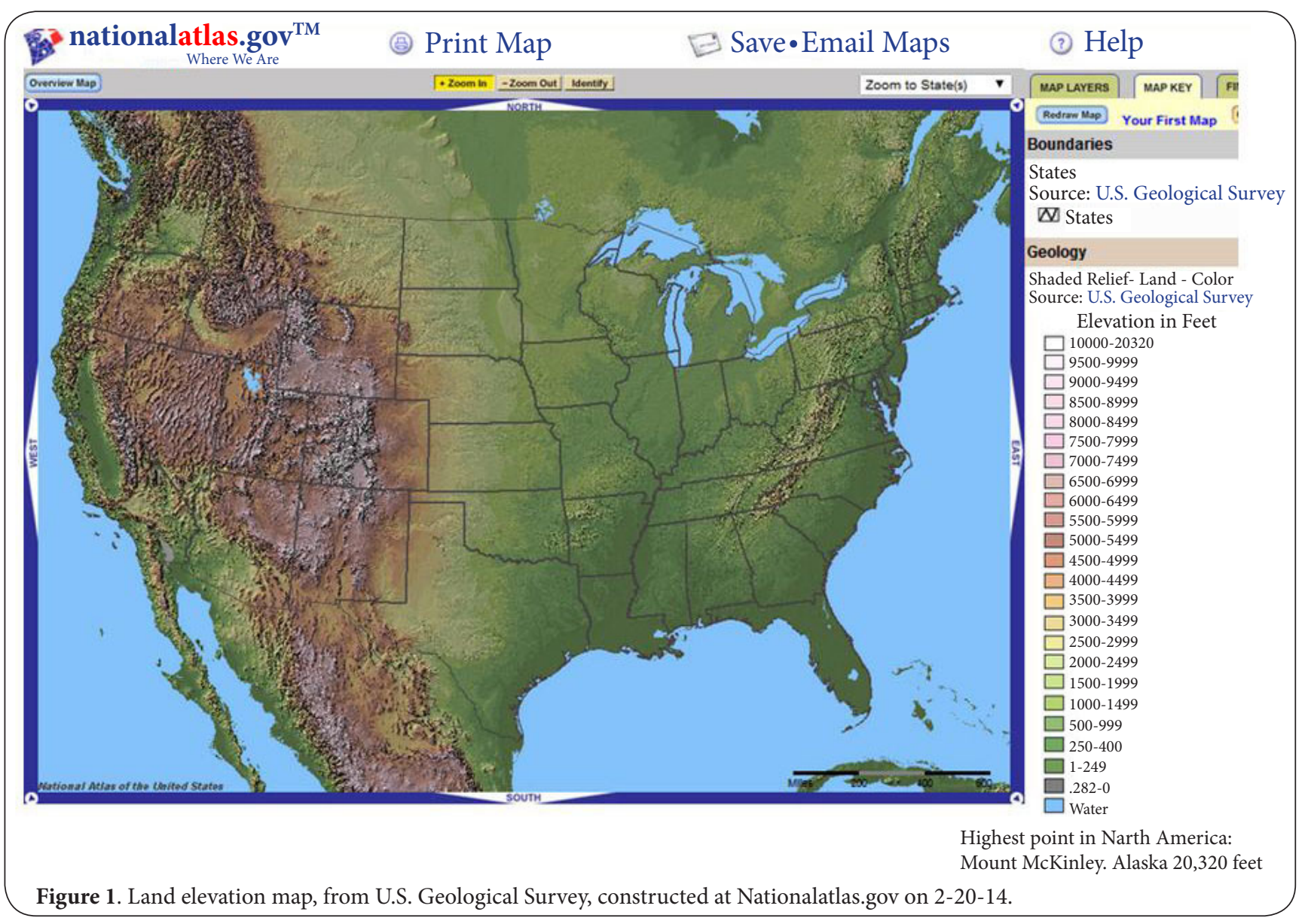


John F. Hart, Epidemiology Reports 2014,

Table 1. Descriptive statistics.

\begin{tabular}{lllllll}
\hline Elevation & State & County & High & Low & Temp & smoke \\
\hline Low & Florida & 67 & 345 & 0 & 71.70 & 23.6 \\
Low & D.C. & 1 & 410 & 1 & 56.50 & $\mathbf{1 1 . 6}$ \\
Low & Delaware & 3 & 448 & 0 & 56.45 & 22.1 \\
Low & Louisiana & 64 & 535 & -8 & $\mathbf{6 8 . 4 0}$ & 23.4 \\
Low & Mississippi & 80 & 806 & 0 & 65.50 & 24.9 \\
Low & Rhode Island & 5 & 812 & 0 & 50.90 & 19.0 \\
Low & Illinois & 102 & 1325 & 279 & 53.60 & 19.6 \\
Low & Indiana & 92 & 1257 & 320 & 53.65 & 23.9 \\
Low & Ohio & 88 & 1550 & 455 & 52.40 & 21.0 \\
Low & Iowa & 99 & 1670 & 480 & 49.30 & 21.0 \\
Low & Missouri & 115 & 1772 & 230 & 56.15 & 22.8 \\
Overlap & New jersey & -- & 1803 & 0 & -- & -- \\
High & Montana & 50 & 12799 & 1800 & 44.25 & 17.2 \\
High & New Mexico & 30 & 13161 & 2842 & 57.10 & 18.9 \\
High & Utah & 28 & 13528 & 2000 & 49.60 & $\mathbf{9 . 1}$ \\
High & Wyoming & 23 & 13804 & 3099 & 43.35 & 20.0 \\
High & Colorado & 59 & 14433 & 3315 & 46.90 & 16.6 \\
Lower fence & -- & -- & -- & -- & 38.84 & 11.76 \\
Upper fence & -- & -- & -- & -- & 67.34 & 29.66 \\
\hline St & &
\end{tabular}

States with non-overlapping land elevations (except for

New Jersey), sorted by highest point in ascending order and categorized into two land elevation categories in the "Elevation" column as low or high. Column titled "High"=highest land elevation point. Column titled "Low"=lowest land elevation point. 0 feet=sea level. New Jersey was not included in inferential statistical analyses ( $t$ test and effect size) but is listed in the table here only as an example of how an overlapping state (land elevation-wise) was identified. New Jersey's high point of 1803 feet overlaps with Montana's low point of 1800 feet. All other states after New Jersey (in ascending order for their high points) would likewise overlap with at least Montana in the high land elevation. D.C.=District of Columbia. Temp=average daily temperature during 2006-2010. Smoke=percent of white adults who were smokers in 2006. Lower and upper fences pertain to outlier analysis for temperature and smoke. Bolded values under Temp and Smoke columns indicate outlier states which were omitted from the $t$ test.

LE counties used in this study. Many of the low LE counties in this study were selected from southeastern states, which have lower land elevations (Figure 1) and warmer air temperatures compared to Rocky Mountain states. According to one source, cancer rates are higher in the south, along a "cancer belt," though air temperature was not mentioned as a possible determinant [9]. The author theorized that air temperature may be associated with the cancer death rates in this study, as evidenced by the aforementioned cancer map (Figure 2). Thus, an accounting of it (air temperature) was included in this study. A comparison of state temperatures was made by:

1. Calculating daily mean air temperatures (in Fahrenheit) for each of the 16 states, for 2006-2010 (to coincide with the cancer death rate years) by averaging the average daily minimum and maximum temperatures, [10] and then inferring this average to the county level.

2. Identifying state temperature outliers (using a factor of 1.5 multiplied by the inter-quartile range) among the 16 states and excluding states from the study that were found to be outliers (Table 1).

\section{Smoking variable}

While there are many potential determinants of cancer such as $L E$ and air temperature, smoking is one of the more notable determinants. Thus, an accounting of smoking at the state level was included in this study, in the form of percent of white adults who were smokers in 2006, [11] and then inferring to the county level. Here too, states that were outliers (for smoking) were omitted (Table 1).

\section{Selection of states}

For a state (and therefore its county cancer death rates) to be included in this study, the following three conditions (detailed above) had to be satisfied at the state level: 1) nonoverlapping land elevation, 2) non-outlier for temperature, and 3) non-outlier for smoking. Thus, a total of four variables were "controlled" (accounted for) in this study: 1) race, 2) land elevation, 3) air temperature, and 4) smoking rates.

\section{Data analysis}

County cancer death rates in qualifying low LE states were compared to county cancer death rates in qualifying high LE states using the following inferential two statistics: 1 ) the two sample $t$ test (with the unequal variances option), and 2) effect size (with pooled standard deviation). Analyses were performed in Excel (Microsoft Corp., Redmond WA) and Stata IC 12.1 (StataCorp, Inc., College Station, TX). P-values less than or equal to the traditional alpha level of 0.05 were considered statistically significant.

\section{Results}

\section{Temperature outliers}

Florida and Louisiana were (high) outliers for temperature (Table 1) and were therefore excluded from inferential analysis (t test).

\section{Black race}

Many states did not have smoking data reported for black persons, particularly in the Rocky Mountain states. Only Colorado, with its five reporting counties for cancer death rates, had a reportable smoking mean, and this mean was not an outlier among the other nine states reporting smoking means. However, an $\mathrm{n}$ of only 5 counties (for the high LE category) was considered insufficient for inferential analysis. For descriptive statistics, mean cancer death rate was 236.2 (standard deviation [SD] 45.9) in LE counties ( $n=147$ counties) compared to a mean cancer death rate of 184.6 (SD 26.2) in high LE counties ( $n=5$ counties).

\section{White race}

District of Columbia and Utah were (low) outliers for smoking 


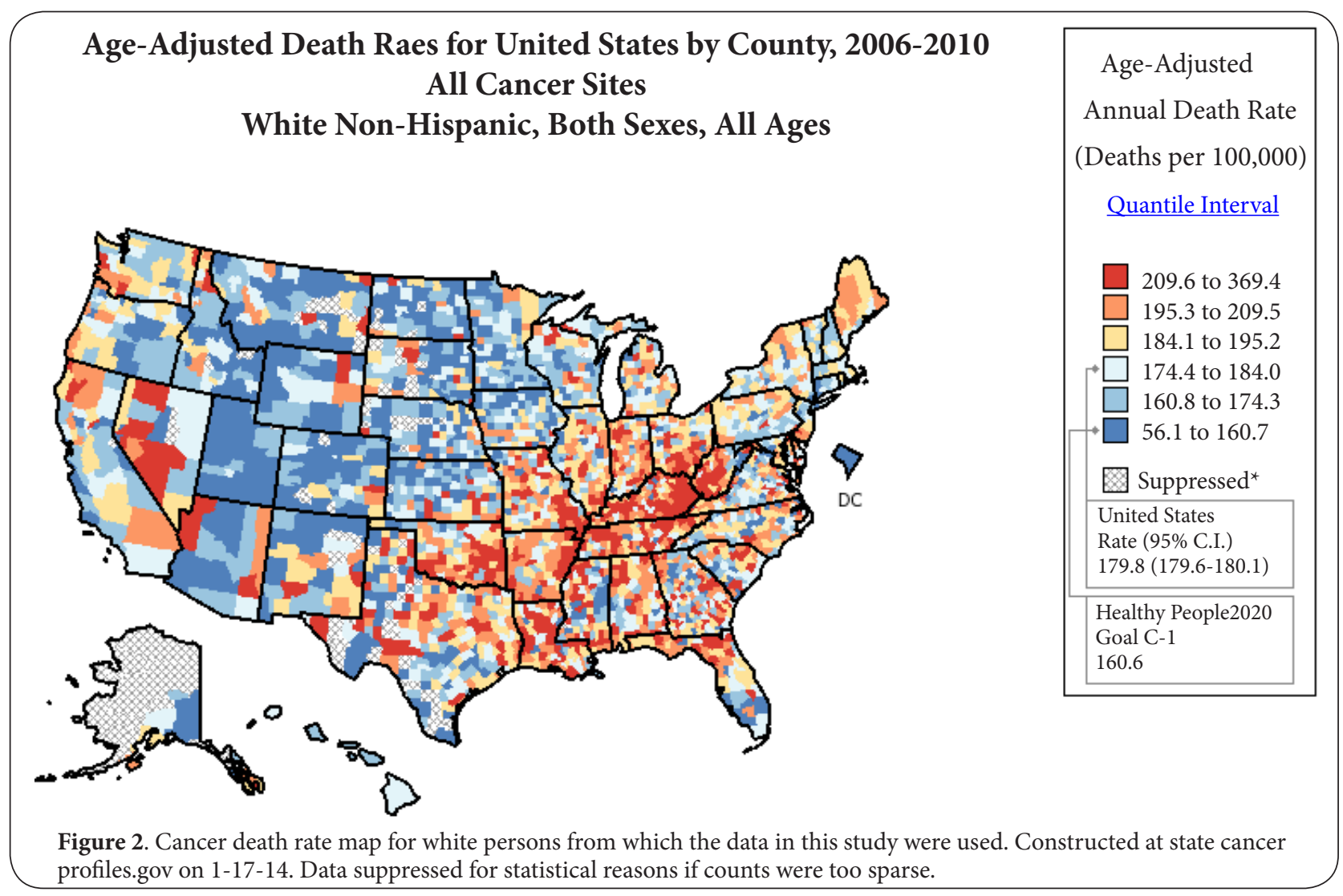

(Table 1). Thus, four "states" (FL, LA, D.C., and UT) were omitted from inferential statistical analyses. Low LE counties were derived from the states of Delaware, Illinois, Indiana, lowa, Mississippi, Missouri, Ohio, and Rhode Island ( $\mathrm{n}=584$ counties). High LE counties were derived from the states of Colorado, Montana, New Mexico, and Wyoming ( $n=162$ counties). The cancer death rate in low LE counties was 189.6 (SD 23.9) compared to the cancer death rate of 161.4 (SD 28.9) in high LE counties, a difference that was statistically significant $(p<0.0001)$ with a large effect size (of 1.12; Table 2).

\section{Discussion}

This ecological study provided a novel, numerically-based method for categorizing states in the U.S. as having: a) low versus high land elevations, b) similar smoking rates, and

Table 2. County cancer death rates for white persons in low versus high land elevation counties.

\begin{tabular}{llll|ll}
\hline Land elevation & County n & Mean & SD & \multicolumn{2}{|c}{ 95\% CI } \\
\cline { 5 - 6 } & & & & Lower limit & Upper limit \\
\hline Low & 584 & 189.6 & 23.9 & 187.3 & 191.1 \\
high & 162 & 161.4 & 28.9 & 157.0 & 165.9 \\
\hline
\end{tabular}

$\mathrm{CI}=$ confidence interval. The difference in cancer death rates between land elevation categories was statistically significant $(\mathrm{p}<0.0001)$ with a large effect size (of 1.12). Evidence of the statistically significant difference is observed with the nonoverlapping confidence intervals. c) similar air temperatures. This accounting, along with an accounting of race, allowed for a reasonable isolation of land elevation (LE) and its possible effect on county cancer death rates.

This study found lower cancer death rates for white persons in higher LE areas compared to lower LE areas. This finding is consistent with typical findings revealed by previous research on effects of $L E$ on cancer death rates. Possible reasons for the decreased cancer death rates at higher land elevations, likely pertain, as previously noted, to the body's striving to not only resist environmental stressors that accompany higher land elevations, but also to successfully adapt to them, using the stressors to its (the body's) advantage. A breakdown by cancer type may reveal a different story. For example, prostate cancer has been found to be higher in northern states (which may have higher land elevations) compared to southern states. [12] Future study on health effects of land elevation should include a breakdown by cancer type.

Regarding the stressor of the altitude (cosmic)-related source of natural background radiation (NBR), the amount of NBR corresponding to altitude changes is estimated to be: 2 millirem (mr) up to 1000 feet in LE, 5 mr for 1000-2000 feet, $9 \mathrm{mr}$ for 2000-3000 feet, and so on [13]. With high levels of ionizing radiation, such as received by persons near the atomic bombings in Japan in 1945, and received by persons near the nuclear power plant accident at Chernobyl in 1986, cancer 
rates likely increase in a linear fashion with increasing exposure. However, with low levels of ionizing radiation, there may be a threshold, below which the body essentially may no longer be susceptible to the harm of the radiation. Indeed, in the low level radiation range, cancer rates may actually decrease with increasing amounts of low level radiation, but obviously only to a point, where the radiation becomes high level, and, as previously noted, the cancer rates would be expected to increase with increasing high levels of radiation in a linear fashion. Others contend that radiation risks are linear, and that there is no threshold in the low level radiation range for which ionizing radiation can be considered safe (referred to as the linear non-threshold model) [14].

Other observations and explanations on health effects at higher altitudes include: a) protective effect against certain causes of death due to adaptation to decreased oxygen pressure [3]; b) protective effect against a number of disorders, including psychiatric disorders because of altitude hypoxia [15], which may be more effective if applied intermittently [16]; and c) risk factor for some conditions, as noted above [4-5]. Thus, effects of living at higher altitudes appear to: a) be a mixture of benefits and risks, and $b$ ) have different possible explanations.

The present study adds to the existing body of evidence that higher land elevations appear to provide a protective effect against cancer death rates in the U.S. Limitations to the study include: a) its (ecological) design, where populations, rather known individuals are studied. Nonetheless, the ecological design is an important step toward further research that uses other designs; $b$ ) an assumption that land elevations remain essentially unchanged over time; that the timing of actual LE measurements need not coincide with years for the death rates; c) the assumption that omitting state statistical outliers for temperature and smoking resulted in two populations and environments (low versus high LE counties) that were essentially the same regarding smoking rates and air temperatures; d) only one race (whites) was studied (with inferential statistics); and e) only one response variable (cancer death rates) was studied.

\section{Conclusion}

Using novel numerical methods for identifying low versus high land elevation states, while accounting for smoking rates and air temperature, this study revealed lower cancer death rates for white persons in higher land elevation counties compared to lower land elevation counties. Ongoing research on possible health effects of land elevation is warranted.

Competing interests

The author declares that he has no competing interests.

\section{Publication history}

Editor: Randall E. Harris, The Ohio State University, USA.

Received: 22-Feb-2014 Final Revised: 26-Mar-2014

Accepted: 30-Mar-2014 Published: 05-Apr-2014

\section{References}

1. Jagger J. Natural background radiation and cancer death in Rocky Mountain states and Gulf Coast states. Health Phys. 1998; 75:428-30. I Article I PubMed

2. Luckey TD. Radiation hormesis: the good, the bad, and the ugly. Dose Response. 2006; 4:169-90. | Article | PubMed Abstract | PubMed Full Text

3. Weinberg CR, Brown KG and Hoel DG. Altitude, radiation, and mortality from cancer and heart disease. Radiat Res. 1987; 112:381-90. | Article | PubMed

4. Ezzati M, Horwitz ME, Thomas DS, Friedman AB, Roach R, Clark T, Murray $\mathrm{CJ}$ and Honigman $\mathrm{B}$. Altitude, life expectancy and mortality from ischaemic heart disease, stroke, COPD and cancers: national population-based analysis of US counties. J Epidemiol Community Health. 2012; 66:e17. I Article I PubMed

5. Brenner B, Cheng D, Clark S and Camargo CA, Jr. Positive association between altitude and suicide in 2584 U.S. counties. High Alt Med Biol. 2011; 12:31-5. | Article | PubMed Abstract | PubMed Full Text

6. Hart J. Cancer mortality in six lowest versus six highest elevation jurisdictions in the u.s. Dose Response. 2011; 9:50-8. I Article I PubMed Abstract | PubMed Full Text

7. National Cancer Institute. Age-adjusted death rates for United States by county, 2006-2010. 2014. I Website

8. U.S. Census Bureau. Section 6, Geography and Environment. Table 366 Statistical Abstract of the United States 2011. I Website

9. Rea DK. The cancer belt: High mortality across the south. Memphis Medical News. 2008. I Website

10. Centers for Disease Control and Prevention. North America land data assimilation system (NLDAS) daily air temperatures and heat index, years 1979-2011. CDC WONDER Online Database, 2013.| Website

11. Centers for Disease Control and Prevention. Behavioral Risk Factor Surveillance System. Prevalence and Trends Data. Adults who are current smokers. 2014. | Website

12. St-Hilaire S, Mannel S and Commendador A, et al. Correlations between meteorological parameters and prostate cancer. Int J Health Geographics. 2010; 9:19. I Article

13. U.S. Environmental Protection Agency. Calculate your radiation dose. 2013. | Website

14. Cardis E, Vrijheid M, Blettner M, Gilbert E, Hakama M, Hill C, Howe G, Kaldor J, Muirhead CR and Schubauer-Berigan M et al. Risk of cancer after low doses of ionising radiation: retrospective cohort study in $\mathbf{1 5}$ countries. BMJ. 2005; 331:77. | Article | PubMed Abstract | PubMed Full $\underline{\text { Text }}$

15. Basovich SN. The role of hypoxia in mental development and in the treatment of mental disorders: a review. Biosci Trends. 2010; 4:288-96. | Article | PubMed

16. Basovich SN. Trends in the use of preconditioning to hypoxia for early prevention of future life diseases. Biosci Trends. 2013; 7:23-32. | Article I PubMed

\section{Citation:}

Hart JF. A method to study the possible effect of land elevation on cancer death rates in the U.S. Epidemiol Rep. 2014; 2:2.

http://dx.doi.org/10.7243/2054-9911-2-2 